\title{
LONG-STANDING CONTINUOUS UNEMPLOYMENT IN MALE PATIENTS WITH PSYCHIATRIC SYMPTOMS
}

\author{
BY \\ P. HALL* AND W. L. TONGE \\ Department of Psychiatry, Sheffield University and United Sheffield Hospitals
}

Concern has been expressed from time to time regarding men who do not work for long periods, and recently several of these individuals have been the subject of comment in the National Press. It is sometimes suggested that this behaviour is due to the Welfare State in which the community supports the dependants of such men, and it must be admitted that the percentage of shifts lost from illness has been found to double within a few weeks after paid sick leave was introduced (Buzzard and Shaw, 1952). On the other hand, investigations of unduly prolonged disablement have reported that in more than one quarter of these men the disability is psychiatric (Collier, 1943; Hewitt, 1949). Surveys of unemployed men with psychiatric disability have stressed the significance of personality traits rather than of formal psychiatric diagnosis (Markowe, Tonge, and Barber, 1955a), the importance of physical disability (Lewis, 1935), and the effect of financial motivations and social context (Maxwell Jones, 1952). Other factors found to be associated with long-term unemployment are poor previous work records (Guttman and Thomas, 1946) and large families (Lewis, 1935).

The individuals who comprise this population of psychiatrically-disabled unemployed men constitute a major therapeutic challenge. Attendance at a special out-patient clinic has been shown to be ineffective (Markowe, Tonge, and Barber, 1955b), although in-patient treatment at a special unit showed more promising results (Maxwell Jones, 1952). The present investigation seeks to delineate further this group of psychiatric invalids and also to assess the value of in-patient treatment.

\section{MeTHOD}

Of 906 consecutive new male patients referred to the United Sheffield Hospitals' Department of

* Powick Hospital, Worcester.
Psychiatry during a 16-month period, 61 patients aged 16-65 years were found to have been continuously unemployed for 12 months or longer. These were compared with 57 male patients of all ages who formed a 5 per cent. sample of the remaining male patients. The progress of these patients was assessed 6 months to 2 years after discharge by a home visit by a Psychiatric Social Worker.

\section{FiNDINGS}

(1) Diagnoses.-These are set out in Table I.

TABLE I

DIAGNOSIS

\begin{tabular}{|c|c|c|c|}
\hline & Diagnosis & $\begin{array}{c}\text { Un- } \\
\text { employed* }\end{array}$ & Control \\
\hline \multicolumn{2}{|c|}{$\begin{array}{c}\text { (a) Depression-with endogenous compo- } \\
\text { nent } \\
\end{array}$} & 9 & 4 \\
\hline (b) Neurosis & 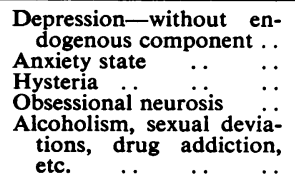 & $\left.\begin{array}{r}3 \\
14 \\
5 \\
2 \\
1\end{array}\right\} 25$ & $\left.\begin{array}{r}10 \\
16 \\
5 \\
4 \\
7\end{array}\right\} 42$ \\
\hline \multicolumn{2}{|c|}{ (c) Schizophrenia and severe subnormality } & 6 & 4 \\
\hline \multicolumn{2}{|c|}{ (d) Serious or total physical disability $\dagger \ldots$} & 21 & 7 \\
\hline Total & .. & 61 & 57 \\
\hline
\end{tabular}

* Following previous work, no distinction is made between un-

employment and sickness absence. pulmonary tuberculosis, hemiplegia, cerebral neoplasm, etc.

The association between unemployment on the one hand and schizophrenia, severe subnormality, and serious physical disability on the other has been demonstrated in previous investigations (Markowe, Tonge, and Barber, 1955a; Lewis, 1935). 
The present investigation confirms the association between unemployment and serious physical disability (Table II).

TABLE II

TOTAL PHYSICAL DISABILITY (ALL UNEMPLOYED AND CONTROL PATIENTS) $\chi^{2}=6.57 ; P<0.02$

\begin{tabular}{ccc|c|c|c}
\hline \multicolumn{3}{c|}{ Total Disability } & & Unemployed & Control \\
\hline Present &. & $\ldots$ & $\ldots$ & 21 & 7 \\
Absent &. & $\ldots$ &. & 40 & 50 \\
\hline Total &. & $\ldots$ &. & 61 & 57 \\
\hline
\end{tabular}

The aim of the present investigation was mainly directed to the patients with depression and neurotic disturbances (sections $(a)$ and (b) of Table I) who constituted a group of 34 subjects (with 46 subjects in the control group with comparable psychiatric diagnoses). The remaining findings refer only to the patients in these two categories.

(2) AGE.-There was an increased proportion of men over 50 years of age in the unemployed group compared with the control group, despite the exclusion of men over 65 from the unemployed group (Table III).

TABLE III

AGE DISTRIBUTION (PATIENTS WITH DEPRESSION OR NEUROSIS ONLY)

$x^{2}=8 \cdot 2 ; P<0.01$

\begin{tabular}{|c|c|c|c|c|c|}
\hline \multicolumn{4}{|c|}{ Age (yrs) } & \multirow{2}{*}{$\begin{array}{c}\text { Unemployed } \\
20 \\
14\end{array}$} & \multirow{2}{*}{$\begin{array}{c}\text { Control } \\
\begin{array}{c}40 \\
6\end{array}\end{array}$} \\
\hline $\begin{array}{l}\text { Under } 50 \\
\text { Over } 50\end{array}$ & .. &. &. & & \\
\hline Total & .. &.. &.. & 34 & 46 \\
\hline
\end{tabular}

(3) OCCUPATION.--All types of non-manual workers comprised 25 of the control group compared with six of the unemployed (Table IV). Nineteen of the unemployed were skilled or semi-skilled and nine unskilled. The commonest occupation was "collier".

TABLE IV

OCCUPATION (PATIENTS WITH DEPRESSION OR NEUROSIS ONLY

\begin{tabular}{|c|c|c|c|}
\hline \multicolumn{2}{|c|}{ Occupation } & \multirow{2}{*}{$\begin{array}{c}\text { Unemployed } \\
\mathbf{6}\end{array}$} & \multirow{2}{*}{$\begin{array}{c}\text { Control } \\
25 \\
21\end{array}$} \\
\hline $\begin{array}{l}\text { Non-manual.: } \\
\text { Manual }\end{array}$ & .. & & \\
\hline Total &.. & 34 & 46 \\
\hline
\end{tabular}

(4) Physical Disability.-Apart from serious or total physical disability, thirteen of the unemployed subjects and seven of the controls were partially disabled from physical disease* (Table V).

TABLE V

PARTIAL PHYSICAL DISABILITY (PATIENTS WITH DEPRESSION OR NEUROSIS ONLY) $\chi^{2}=4.36 ; \mathrm{P}<0.05$

\begin{tabular}{|c|c|c|c|c|c|}
\hline \multicolumn{4}{|c|}{ Partial Physical Disability } & \multirow{2}{*}{ 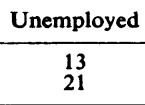 } & \multirow{2}{*}{$\begin{array}{c}\text { Contro } \\
7 \\
39\end{array}$} \\
\hline $\begin{array}{l}\text { Present } \\
\text { Absent }\end{array}$ & $\because$ & 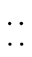 & $\therefore$ & & \\
\hline Total & $\cdots$ & $\cdots$ & $\ldots$ & 34 & 46 \\
\hline
\end{tabular}

(5) Paternal Deprivation.-Only in patients suffering from neurotic and allied disorders (section $(b)$ of Table I) was association found between loss of the father before the age of 9 years (by death, desertion, or illegitimacy) and unemployment (Table VI).

TABLE VI

PATERNAL DEPRIVATION (NEUROTIC SUBJECTS ONLY) $\chi^{2}=3.88 ; \mathrm{P}<0.05$

\begin{tabular}{|c|c|c|c|c|c|c|}
\hline \multicolumn{5}{|c|}{ Paternal Deprivation } & \multirow{2}{*}{$\begin{array}{c}\text { Unemployed } \\
9 \\
16\end{array}$} & \multirow{2}{*}{$\begin{array}{c}\text { Control } \\
4 \\
38 \\
\end{array}$} \\
\hline $\begin{array}{l}\text { Yes } \\
\text { No }\end{array}$ & 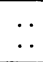 & $\begin{array}{l}\ldots \\
\cdots\end{array}$ & $\cdots$ & $\begin{array}{l}\cdots \\
\cdots\end{array}$ & & \\
\hline & otal & $\cdots$ & . & . & 25 & 42 \\
\hline
\end{tabular}

(6) OTHER DifFerenCES.-The unemployed tended to have more children and more siblings than the control group, and were more likely to live outside the city boundaries. There was also a more frequent family history of psychiatric illness amongst the unemployed. None of these differences, however, reached a statistical level of significance. About one-quarter of both groups had had previous psychiatric treatment, and 79 per cent. of the unemployed and 76 per cent. of the control group were married.

\section{(7) OTher Features of THE UNemployed}

(a) Income.-Average income while not working was approximately $£ 8$ p.w. (compared with $£ 10$ p.w. while working). This did not include the wages of other family members and unassessed income such as the colliers' free coal, payment for odd jobs, and the savings in fares from not working. In eleven cases the womenfolk went out to work, and most of the patients spent their time gardening, playing with the children or their dogs, pigeon-keeping, etc.

\footnotetext{
* Comprising such conditions as chronic peptic ulcer (six patients) unilateral retinal detachment, chronic bronchitis, amputation of a leg, etc.
} 
(b) Father's Occupation.-Some patients did not know their father's occupation since so many had lost their father early, but it was ascertained in 25 cases. In no case had there been much change in occupational status between father and son; six fathers had been unskilled, twelve semi-skilled, five skilled, and two routine non-manual workers.

(c) Precipitating Event of Unemployment.-Accidents, illness, and bereavement were the precipitating events of unemployment in over half the subjects (Table VII).

TABLE VII

EVENT PRECIPITATING UNEMPLOYMENT (PATIENTS WITH DEPRESSION AND NEUROSIS ONLY)

\begin{tabular}{|c|c|c|c|c|c|c|}
\hline \multicolumn{5}{|c|}{ Precipitating Event } & \multicolumn{2}{|c|}{ No. of Cases } \\
\hline Promotion & .. & .. & $\ldots$ & $\ldots$ & . & 1 \\
\hline Dismissal .. & . & . & .. & . & . & 2 \\
\hline Bereavement & .. & .. & .. & $\ldots$ & . & 5 \\
\hline Physical Illness & .. & . & & $\begin{array}{l}\text { ent } \\
\text { tion } \\
\ldots \\
\end{array}$ & $\because$ & 13 \\
\hline \multicolumn{4}{|c|}{ No Apparent Precipitating Cause } & . & $\cdots$ & 13 \\
\hline Total & 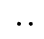 & .. & .. & . & . & 34 \\
\hline
\end{tabular}

\section{TREATMENT}

Patients were admitted to hospital (average stay 8 wks) and a "total push" régime was instituted. Superficial psychotherapy (1-2 hours weekly) was an adjunct of this. Many of these men were past masters at manipulating professional helpers and close informal personal contact was therefore maintained between all personnel.

(1) Occupational Therapist.-The therapy consisted of graduated work and never of handicrafts. It was emphasized that this work was treatment and had been prescribed by the doctor and was not merely diversion. For practical reasons the work usually consisted of gardening.

(2) Psychiatric Social Worker.-The psychiatric social worker dealt with any social and financial problems of the patient and his family, while preparing the patient's relatives for a reshuffling of conjugal and family roles, i.e. that the father was no longer to be regarded as an invalid.

(3) Disablement Resettlement Officer.-The patient was interviewed in the latter part of in-patient treatment and the officer attempted to place him in suitable work to start immediately on discharge. "Convalescence" was particularly discouraged. Both the Disablement Resettlement Officer and the
Psychiatric Social Worker continued to keep in touch with the patient after discharge. In a very few cases attendance at an Industrial Rehabilitation Unit was arranged.

(4) Psychiatrist.-A careful history and full physical assessment were carried out, and all psychiatric treatment was usually withdrawn. The patients' complaints were sympathetically heard and no attempt made to deny the subjective reality of symptoms. Each patient was given a simply formulation of his present situation and told that chronic unemployment was making his psychiatric condition worse. He was told that immediate return to some gainful occupation was necessary and was authoritatively reassured regarding his capability for this. The financial, medical, and prestige advantages of employment were reiterated, and the more he complained of neurotic symptoms the more urgent return to work was pronounced to be. The patient's wife was interviewed and an attempt made to enlist her help in rehabilitation and in making a change in the family constellations. The patient was seen regularly during his in-patient stay, usually for 1 to 2 hours a week, the aim of therapy being not to change a neurotic patient into a non-neurotic (this only provoked hostility and resentment), but an unemployed psychoneurotic into an employed one.

(5) Nurses.-The nursing staff took up a supportive and encouraging role in which occupational therapy was always spoken of as "your treatment" to the patient and was equated with the electroconvulsive therapy, drugs, etc., by which other patients were being treated.

\section{OUTCOME AND Follow UP}

Thirteen patients were actually working at the time of the follow-up inquiry. Altogether sixteen of the 34 patients had returned to work, but in four employment was interrupted. Of the eighteen patients who were not known to have returned to work, one could not be traced (but there were some grounds for believing that he was in work) and one was in a sanatorium (Table VIII).

TABLE VIII

RESULTS IN PATIENTS FOLLOWED-UP AFTER TREATMENT (DEPRESSION AND NEUROSIS ONLY)

\begin{tabular}{|c|c|c|c|c|c|}
\hline \multirow{2}{*}{\multicolumn{2}{|c|}{ Diagnosis }} & \multicolumn{4}{|c|}{ Occupation } \\
\hline & & Working & $\begin{array}{c}\text { Not } \\
\text { working }\end{array}$ & $\begin{array}{c}\text { In } \\
\text { hospital }\end{array}$ & $\begin{array}{c}\text { Not } \\
\text { traced }\end{array}$ \\
\hline $\begin{array}{l}\text { Depression } \\
\text { Neurosis . }\end{array}$ & 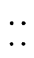 & $\begin{array}{r}4 \\
12\end{array}$ & $\begin{array}{r}5 \\
11\end{array}$ & $\overline{1}$ & $\overline{1}$ \\
\hline Total ... & $\ldots$ & 16 & 16 & 1 & 1 \\
\hline
\end{tabular}


There seemed to be little difference in the proportion returning to work between patients with endogenous depression and those with neurotic disorders. With the latter diagnosis, however, there was an interesting correlation with age. Excluding the patient who was still in the sanatorium and the patient who could not be traced, there remained 23 patients with neurotic disorders.

Eleven of these were aged 40 or over at the time of referral and only one had resumed work, but of the twelve aged under 40 years, eleven had returned to work. This difference is statistically significant (Table IX). The average weekly income of patients who returned to work was $£ 10$ 10s. as compared with f8 12s. for those not working. The clinical condition of patients at the time of follow up varied according to the diagnosis. Of the nine patients with endogenous depression, seven were much improved and this included those who had returned to work. Among the patients with mainly neurotic symptomatology there was some improvement in the symptoms of those who returned to work but none of them lost their symptoms completely, which underlines the aim of the treatment to improve their social adaptation rather than to remove symptoms.

TABLE IX

RESULTS IN NEUROTIC PATIENTS WITH ADEQUATE FOLLOW-UP, BY AGE

$x^{2}=9.45 ; \mathrm{P}<0.01$

\begin{tabular}{|c|c|c|c|c|c|}
\hline \multicolumn{4}{|c|}{ Age (yrs) } & \multirow{2}{*}{ 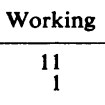 } & \multirow{2}{*}{ 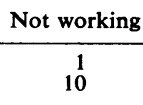 } \\
\hline $\begin{array}{l}\text { Under } 40 \\
\text { Over } 40\end{array}$ & 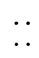 & $\begin{array}{l}\ldots \\
\cdots\end{array}$ & $\begin{array}{l}\ldots \\
\cdots\end{array}$ & & \\
\hline Total & .. & . & $\ldots$ & 12 & 11 \\
\hline
\end{tabular}

\section{Typical Case Histories}

Case 1, a man aged 55, suffered from an endogenous depression and was able to return to work after adequate psychiatric treatment. He was first seen in February, 1959, when he complained of dyspepsia, "feeling low", and lack of zest for 5 years. There had been no weight loss, sleep disorder, or suicidal ideas. He was treated by support and Drinamyl as an out-patient and gradually improved over the next few months but did not return to work (having been off work for 2 years). He failed to keep several appointments at the beginning of 1960 . He had always been a quiet, passive, lonely man, who worked as a self-employed knife-hafter (the family business) but was really only interested in his dance band. His wife worked as a clerk and had supported him while he had been off work. There were no children. He had suffered from a chronic peptic ulcer for many years. In February, 1961, his father died and he became much more depressed, retarded, and agitated. He was admitted and eventually agreed to have E.C.T. He improved rapidly and became a little hypomanic. He was discharged in May, 1961, and continued to improve but procrastinated about working. In September, 1961, he started working 4 or 5 hours a day and was still doing so in March, 1962. He was asymptomatic, off all medication, and planning to restart his dance band.

Case 2, a man aged 36, was a neurotic whose social attitudes improved considerably with in-patient treatment and who returned to work. He first attended as an out-patient in July, 1961, when he complained of generalized pains and aches for 4 years and was a registered disabled person ("fibrositis"). He had not worked since 1957, his last job being as a gardener. He was a scythemaker by trade, but since 1946 when he left the Army had had a very poor work record (fifteen jobs) and was disgruntled and irritable. He lived in a grossly overcrowded condemned house with six children. His marriage was happy enough, considering the overcrowding, etc., and his income (National Assistance) was £9 weekly. He had been an only child and had always been anxious and lonely. He had been brought up by his maternal grandmother, since his father died when he was 12 and mother went out to work. Both he and his wife said quite frankly that he could not expect to earn more by working and were busy looking after their large family. He seemed an intelligent man, very much master of his household, but his attitude to society was interesting. He felt that the city had treated him shabbily by not provid ing more, and threatened to move elsewhere unless they "played the game". He was not hostile about this but felt rejected and misunderstood. After in-patient treatment (26 July to 3 October, 1961) he improved a good deal and made bona fide attempts to find work. He said the therapist was "like mother-sensible" and found work as a kitchen porter in November, 1961.

Case 3, a man aged 48, suffered from neurosis complicated by physical disease, and showed no improvement. He attended as an out-patient in November, 1959; he had suffered from peptic ulcer symptoms for many years and had a perforation in 1929. He had always been an obsessional, anxiety-prone, and hypochondrical man, and since a partial gastrectomy in 1956 he was not worked. He complained of dyspnoea, weakness, and right-sided abdominal pain. In 1958 he had a further operation but with no effect on his symptoms. He lived in a Yorkshire village where the only industry was coal mining, and until 1956 had worked as a collier and had been well thought of, but had been attending various physicians and surgeons since 1930. In interviews he admitted that he had always detested mining but had been forced into it by circumstances and by his father. He was married and had five children of whom three daughters were working and contributing to the household. In addition his income was $£ 6$ 14s. from unemployment benefit, etc. (When working he earned from $£ 815 \mathrm{~s}$. to $£ 25$ a week.) He spent his time "pottering about", gardening, walking, and watching T.V. He lived in a National Coal Board house and had an allowance of free coal. During his stay in hospital he improved a little and gained some weight. He was also 
found to have moderately severe chronic bronchitis but thorough physical investigation revealed no other physical disease. His wife was a pleasant but somewhat dominating woman who made all the household decisions and the patient's mother had apparently been very similar. He was discharged in September, 1960, with his condition unchanged, but he talked vaguely of "looking round for a light job". Soon afterwards he saw yet another surgeon who found he had a mobile right kidney and prescribed a support but this did not affect his symptoms. At follow up in 1962 there had been no change in his condition.

Case 4, a man aged 37, suffered from neurosis with physical disability, and improved sufficiently to return to work. He was first seen in June, 1958, when he complained of fears of leaving the house, and headaches for 3 years, since leaving the R.A.F. These symptoms had been increasing in severity and he had been unable to work for a year. He worked as a labourer in an engineering works, but did not like the noise of machinery and had attended the industrial resettlement unit for 10 weeks without benefit. He had always been anxious, was enuretic until aged 12, and had a limp caused by tuberculosis of the hip when he was 9 years old. He was the youngest of eleven children and had had an unhappy childhood, his father having died when he was 5 and his allegedly cruel stepfather when he was 12 . He was said to be happily married and had four children. Since he had been off work his wife had worked as a charwoman for $£ 2$ weekly and unemployment benefit and family allowances came to another $£ 74 \mathrm{~s}$., where his weekly wage had been $£ 9$. He gradually improved and by August, 1960, was applying for jobs but was always "unlucky". His main complaint was of travel phobia. He did little at home and spent most of his day taking his dog for walks. In January, 1962, he suddenly improved and found himself a job as a car washer.

\section{Discussion}

Many of the findings of the present study are similar to those of previous investigators. A high incidence of depression and anxiety was reported by Lewis (1935), Eisenberg and Lazarsfeld (1938), and Markowe, Tonge, and Barber (1955a). Lewis (1935) also found a high proportion of physical illness comparable to the findings of this study. It was noteworthy that, even among patients not physically disabled at the time of referral, the giving up of work had often been precipitated by an accident or injury, sometimes with certain features of "accident neurosis" (Miller, 1961). It may be of importance that many patients were miners. Carstairs and Brown (1958) comment that the underground workers were the élite in colliery areas, and it is possible in this study that psychoneurotic invalidism is a useful face-saving procedure in escaping from the dangerous but profitable work at the coal face.
In this study, the married unemployed patients had relatively large families, and this also was found by Lewis (1935). Family size is no doubt related to the age and social class of these patients, but the increase in unearned income may be important also. This leads to a shrinking of the financial incentive to return to work. $£ 2$ is a small enough stimulus, when it also has to pay for fares and a mid-day meal. Similar findings were reported by Markowe, Tonge, and Barber (1955a), but the present study includes fewer unmarried subjects.

Actual reversal of the domestic roles was rare, and the much more usual state of affairs was a regression, with the women taking on both breadwinning and housekeeping roles, while the patients led a leisured and protected existence. Rearrangement of these roles was in fact the chief aim of treatment. Major psychotherapy was not undertaken, since such patients with low morale and prolonged invalidism and therefore poor prognosis could be said to have relatively little claim on the limited psychotherapeutic time available.

One of the less expected findings of this investigation was the fate of the psychoneurotic invalids with prolonged unemployment. Age seemed to be (unlike the finding of Harris and Lane, 1949) an important prognostic factor, with 40 years appearing as a "threshold" age. The results among the patients aged under 40 of the simple régime described suggest that in this group of patients an unduly pessimistic prognosis is not warranted. This is in contrast to the experience of Markowe, Tonge, and Barber (1955b), who offered only out-patient care, and emphasizes the need for in-patient treatment. The critical point after treatment seemed to occur when the patient had been back at work for a few months and his employer objected to his attendance at out-patients. This no doubt contributed to the high relapse rate and perhaps could be overcome by holding an evening clinic or by treating these patients as a group at evening meetings. The necessity for close liaison between doctor and employment exchange must again be noted (Harris and Lane, 1949).

An unexpected finding was the relatively high incidence of "paternal deprivation". Parental deprivation (not specifying which parent) has been shown to be uncorrelated with unemployment in psychiatric patients (Tonge, 1954). It seems possible that a weak or missing father may present a relative difficulty in maintaining the masculine role of being the breadwinner, perhaps leading to a pre-disposition to the choice of this particular neurotic symptom when under stress (Maxwell Jones, 1952). A somewhat similar mechanism has been postulated for the sociosexual incapacity of the homosexual (West, 1960). 
Research into the psychiatry of the unemployed must seek out characteristic syndromes. The importance of personality inadequacy has already been described (Tonge, 1955). Paternal deprivation, if confirmed, may be another important factor. Much still remains to be explained; most of the patients in this series had a stable work record before the unemployment started, and in many of these it would have been difficult to predict the response of unemployment to psychiatric illness. The importance of a clear financial incentive to work, well above the level of unemployment benefit, is obvious.

Although these men may not constitute numerically a very large group in present-day conditions of nearly full employment, they are disabled by a potentially reversible illness and constitute a disproportionately heavy drain on their families, welfare agencies, and the community. It may be that, with more intensive and prolonged psychotherapy, more satisfactory results could have been obtained. While this cannot be excluded, the average psychiatric department has only limited resources in this direction. The therapy of the unemployed invites further attention.

\section{SUMmary}

Among 906 consecutive male psychiatric patients in Sheffield, 61 had been unemployed for one year or more and 34 of these were under 65 years old and presented with neurotic and depressive symptoms. They have been compared with a control group of male psychiatric patients. Significantly more of the neurotic group had lost their fathers before age 9 than of the control group and the neurotics were also older on the whole, showed a higher proportion of physical disability, and tended to have more children if married. They were mainly manual workers. Prognosis appears to depend largely on age. A simple régime of treatment and its results are described, as well as a 1 to 2 year follow up.

We are indebted to Prof. E. Stengel for advice and encouragement. Mr. W. Lee, Miss M. A. Arneill, and Sister Vincent carried out all the follow-up visits. We are most grateful to them, as well as to our occupational therapists, Miss M. Smith and Miss J. Watts, and to the nursing staff of the Whiteley Wood Clinic, Sheffield, for their help and co-operation in the study. The D.R.O. service of the Ministry of Labour, especially Mr. N. Crapper, gave invaluable assistance. The work on this project carried out by P.H. was done during his tenure of a Foundation Fund Research Fellowship in Psychiatry, University of Sheffield.

\section{REFERENCES}

Buzzard, R. B., and Shaw, W. J. (1952). Brit. J. industr. Med., 9, 282.

Carstairs, G. M., and Brown, G. W. (1958). J. ment. Sci., 104, 72.

Collier, H. E. (1943). Brit. med. J., 2, 461.

Eisenberg, P., and Lazarsfeld, P. F. (1938). Psychol. Bull., $35,358$.

Guttman, E., and Thomas, E. L. (1946). "The Readjustment in Civil Life of Soldiers discharged from the Army on account of Neurosis", Min. of Hlth. Rep. on Publ. Hlth and Med. Subj., No. 93. H.M.S.O., London.

Harris, A., and Lane, M. A. (1949). Brit. med. J., 1, 982.

Hewitt, M. (1949). Lancet, 2, 523.

Jones, M. (1952). "Social Psychiatry". Tavistock Publications, London.

Lewis, A. (1935). Lancet, 2, $293-7$.

Markowe, M., Tonge, W. L., and Barber, L. E. D. (1955a). Brit. J. prev. soc. Med., 9, 39-45.

(19, (1955b). Ibid., 9, 46-47.

Miller, H. (1961). Brit. med. J., 1, 919, 992.

Tonge, W. L. (1954). "Psychiatric Illness and Employment". Unpubl. M.D. Thesis, Victoria University of Manchester.

- (1955). Brit. med.J., 1, 1066.

West, D. J. (1960). "Homosexuality", rev. ed., p. 130. Penguin Books, Harmondsworth, Middlesex. 